\title{
Apocalípticos e Integrados
}

\section{Apocalyptic and Integrated}

\author{
Eugenio Matiasevic • Bogotá, D.C. (Colombia)
}

En la escena 81 de una famosa "película de romanos", como denominamos en castellano un género cinematográfico que la industria de Hollywood, de manera ampulosa, insiste en llamar Historical Epics, en una de las alas de un palacio de cartón-piedra diseñado por John De Cuir (1) que no se ciñe al estilo arquitectónico de la dinastía Ptolemáica pero creó todo un estilo en pleno siglo XX (2), Elizabeth Taylor observa en un rollo de papiro el dibujo de un cuerpo humano contorsionado a cuyo pié hay un texto ilegible en el que alcanzan a reconocerse caracteres griegos. A su lado, Hume Cronyn, quien se haría famoso como Polonio en el no menos famoso Hamlet de Richard Burton (3), le enseña que los griegos de los primeros tiempos llamaron epilepsia a esa enfermedad y consideraron favorecidos por los dioses a quienes la padecían. En ese momento irrumpe Cesare Danova en la habitación y le informa a Elizabeth Taylor que los Romanos han incendiado la flota egipcia anclada en el puerto, que el fuego se ha extendido a algunos de los barrios de la ciudad y que, finalmente, ha alcanzado la biblioteca. Seguida de cerca por Hume Cronyn, Elizabeth Taylor corre de inmediato hacia otro cuarto, desde donde pueda estimar la extensión de los daños. No hace falta que nos muestren la biblioteca llameante, ni que Elizabeth Taylor se asome a la terraza: en el cuarto los reflejos de las llamas crean ominosas formas sobre las paredes y sobre el cielo raso, mientras Hume Cronyn, con lágrimas en los ojos, enumera "as if recalling dead children" ("como si recordara hijos muertos", acota el guión), los textos que alimentaron esas llamas y que, en muchos casos, desde entonces sólo son ceniza: "Aristotle's manuscripts... the Platonic commentaries... the plays... the histories... the testament of the Hebrew God... the Book of Books..." ("Los manuscritos de Aristóteles... los comentarios Platónicos...las tragedias... las historias... el testamento del Dios Hebreo... el Libro de los Libros...”). Furiosa, Elizabeth Taylor abandona su apartamento y se dirige por los pasillos del palacio de cartónpiedra hacia otro apartamento en el mismo palacio, al que llega después de sortear con fiereza a dos grupos de extras disfrazados de pretorianos que tratan de impedirle el paso. Al cruzar el umbral, se encuentra en la escena 85 en una habitación circular en la que Rex Harrison, reunido con otros actores vestidos de oficiales romanos, observa unos planos de batalla.

Elizabeth Taylor le reclama con aspereza no haber enviado a todos los soldados romanos a apagar el fuego que consume la biblioteca pero Rex Harrison, fastidiado, le responde que está muy ocupado para atender sus niñerías. Entonces, con furiosa calma, Elizabeth Taylor se enfrenta a todo el grupo y los increpa: "I possible, I would like to define in termes simple enough to be understood by you hulking all-conquering heroes what a library is..." ("Si es posible, me gustaría definir en términos lo suficientemente simples para ser entendidos por ustedes, descomunales héroes conquistadores-de-todo, qué es una biblioteca...”), y continúa: "I wonder... have any of you ever heard of something called a thought? An idea? A phylosophic principal? A book? A poem? A play? A simple sunset told in words that only one man in all of time will use to tell it?" (“¿Alguno de ustedes ha oído alguna vez de algo llamado un pensamiento? ¿Una idea? ¿Un principio filosófico? ¿Un libro? ¿Un poema? ¿Una tragedia? ¿Un simple crepúsculo dicho en palabras que, en toda la historia, sólo un hombre empleará para describirlo?"). Rex Harrison y sus acompañantes quieren volver sobre sus planos de batalla pero Elizabeth Taylor continúa inflexible, ahora sí, subiendo una escala el tono de voz: "How dare you and the rest of your barbarians set fire to my library? Play conqueror all you want, Mighty Caesar! Rape, murder, pillage thousands, even millions of human beings! But neither you nor any other barbarian has the right to destroy one human thought!" " ¿Cómo te atreves
Dr. Eugenio Matijasevic: Editor General, Acta Médica Colombiana. Bogotá, D.C. (Colombia)

E-mail: eugenio.matijasevic@gmail.com Recibido: 26/VII/2011 Aceptado: 26/VII/2011 
tú y el resto de tus bárbaros a incendiar mi biblioteca? Juega al conquistador todo lo que quieras, ¡poderoso César!, viola, asesina, roba a miles, incluso a millones de seres humanos !pero ni tú ni ningún otro bárbaro tiene el derecho de destruir un sólo pensamiento humano;").

Este solo fragmento de la escena 85, que no aparece completo en el filme pues, como tantas otras escenas, también fue recortado para ajustar el tiempo de exhibición a las necesidades de distribución fílmica de la época, nos alienta a privilegiar el guión de esta obra (4) muy por encima de su formato cinematográfico que, a más de abusar flagrantemente del contexto histórico al servicio de emociones infatuadas, no es otra cosa que abalorios, despilfarro extravagante y suntuaria desmesura: arte kitsch, "parodia de la catarsis" como diría Theodor Adorno (5). Al final de la escena, Rex Harrison hace salir a sus oficiales y, sin hacer caso al ruego de Elizabeth Taylor de que salve la biblioteca, después de asegurarle que él puede hacer con ella lo que quiera, con cierta medida violencia la besa por primera vez sin que oponga resistencia; a continuación ella finge una protesta inane preguntándole con ironía si ese beso vale por la deuda que Egipto tiene con él, y él vuelve a besarla mientras, al fondo, sigue ardiendo para siempre la biblioteca, borrada, según la narrativa de Hollywood tan poco afín por la precisión histórica, por los besos de Julio César y Cleopatra.

Porque en efecto, la película de la que he venido hablando es la Cleopatra de Mankiewicz (6). En ella Elizabeth Taylor representa a Cleopatra, último vástago de la estirpe de los Ptolomeos en gobernar realmente a Egipto (ni Cesarión, su hijo con Julio César, ni Cleopatra Selene, ni Alejandro Helios, ni Ptolomeo Filadelfo, sus hijos con Marco Antonio, accederían jamás al trono, y después de ella ya no habrá Egipto sino Provincia de Egipto del Imperio Romano); Cesare Danova interpreta a Apolodoro de Sicilia, confidente de Cleopatra; Hume Cronyn es Sosígenes de Alejandría, uno de los Astrónomos consultados por Julio César, refiere Plinio el viejo, cuando estableció el calendario Juliano (7); Rex Harrison, cómo no, es Julio César; y, finalmente, el palacio de cartón piedra es el Palacio Real de los Ptolomeos en Alejandría y la biblioteca en llamas es la Biblioteca de Alejandría.

Son muy disímiles y fragmentarios los informes que nos han llegado desde el pasado sobre el incendio de la Biblioteca de Alejandría. Algunos autores ni siquiera lo mencionan, mientras otros hablan de un numero increíble de libros perdidos para siempre.

En sus Comentarios sobre la Guerra Civil, Julio César se limitó a decir que obtuvo la victoria luego de incendiar "todas aquellas naves y otras que estaban en los astilleros, puesto que no era posible custodiar tan larga extensión con tan pocas fuerzas, e inmediatamente desembarcó sus soldados en Faro" (8). El incendio de la biblioteca es pasado por alto con un descarado silencio. La tergiversación de los hechos y la manipulación de la historia a su favor es una de las actividades favoritas (y necesarias para la preservación del poder) de los poderosos y de sus áulicos.
Estrabón, contemporáneo de los hechos, tampoco se refirió en su Geografía al incendio de la biblioteca. Lo extraño es que, con motivo de sus viajes y exploraciones, vivió por lo menos dos años en Egipto y no solo no menciona el incendio sino que tampoco menciona la biblioteca. Ese extraño silencio parece más bien un silencio deliberado pues, a pesar de su origen griego y de que toda su familia era antiimperialista, Estrabón siempre estuvo del lado de César Augusto (llamado Octavio hasta comienzos del Imperio después del asesinato de Julio César, quien en ese momento, muerto ya, también cambió de nombre: a partir de entonces se llamará Divus Cesar, el Divino César). La adhesión de Estrabón al régimen Imperial fue tal que muchos lo consideran no sólo un buen geógrafo sino también un excelente propagandista del Imperio (9).

En La Farsalia, poema épico inspirado en las guerras civiles romanas, escrito por Lucano unos 100 años después del incendio de la biblioteca, aparece Julio César sitiado dando la orden de incendiar las naves arrojándoles teas de alquitrán a los costados y describe de qué manera el fuego se extendió a los mástiles y a las velas y de allí a los techos de las casas vecinas y voló de techo en techo tan veloz como un meteoro, pero no menciona el incendio de la biblioteca (10). La Farsalia es el primer poema épico en el que no intervienen los dioses mezclándose con los hombres como en las epopeyas clásicas y, además, a diferencia de aquellas, no parece haber un único héroe protagonista (y si lo hay, no es en todo caso Julio César, parecería más bien que fuese Pompeyo, defensor de la república). Por tanto, en este caso sería difícil afirmar que el lapsus amnésico sobre el incendio de la biblioteca sea un silencio cómplice como el de Estrabón, tratando de encubrir al fundador del Imperio, pues las inclinaciones políticas de Lucano parecían ir exactamente en la dirección contraria; de hecho, parece que su antiimperialismo fue la razón para que Nerón ordenara su muerte a la temprana edad de 25 años (otros afirman que fue por celos poéticos).

Aunque escribió 175 años después de los hechos, Apiano fue quien más ordenadamente describió los sucesos que antecedieron al incendio de la Biblioteca de Alejandría. En su Historia Romana: Guerras Civiles (11), refiere que Ptolomeo XII, antes de morir, nombró coherederos del Reino de Egipto a sus dos hijos mayores: Cleopatra VII, de 18 años de edad, y Ptolomeo XIII, de apenas 10 años, quienes contrajeron matrimonio antes de asumir el trono como era costumbre entre los Ptolomeos y, en general, entre los miembros de todas las dinastías faraónicas. Pero Ptolomeo XIII, incitado por Teódoto de Chios, su mentor, y con el apoyo de Potino, su tutor mientras alcanzaba la mayoría de edad, y de Aquilas, comandante en jefe del ejército, embarcó a su pueblo en una guerra civil fratricida tratando de excluir del poder a su hermana mayor y legítima esposa. Expulsada del trono compartido y del país, Cleopatra se refugió en las fronteras de Egipto con Siria tratando de reunir un ejército, en el preciso momento de la historia en que Julio César venció de manera definitiva a Pompeyo en la batalla de Farsalia. Seguido de cerca por Julio 
César, Pompeyo huyó a Alejandría confiando que los hijos de su antiguo aliado Ptolomeo XII le brindarían apoyo, pero al llegar allí, por consejo de Teódoto y tratando de agradar a César para que lo favoreciera en el pleito que mantenía con su esposa y hermana, Ptolomeo XIII hizo asesinar a traición a Pompeyo. Al llegar Julio César a Alejandría recibió como presente de Ptolomeo XIII la cabeza de Pompeyo, pero no sólo no se dejó seducir por el macabro regalo sino que se instaló en el Palacio Real de Alejandría como Cónsul de Roma con el propósito de dirimir el pleito entre hermanos (y de paso cobrarle a Egipto una vieja deuda para poder pagar los gastos de sus tropas) y ordenó dar muerte a los instigadores del "asesinato ilegal de Pompeyo". Potino y a Aquilas fueron muertos de inmediato, mientras que Teódoto fue crucificado meses más tarde por orden de Julio César, después de esconderse un tiempo en Asia. Aunque Apiano no describió en sus Guerras Civiles el incendio de la Biblioteca de Alejandría y, además, pasó con prisa y de manera fragmentaria por la relación entre Julio César y Cleopatra, prometió allí que en su Historia de Egipto se detendría en cada detalle de esta historia.Lamentablemente los cuatro libros de la Historia de Egipto de Apiano desaparecieron, posiblemente en otro de los incendios de la Biblioteca de Alejandría, y nunca sabremos si escribió o no sobre el primero de ellos.

Plutarco no es tan prolijo como Apiano con respecto a los antecedentes del incendio de la Biblioteca de Alejandría, pero en César, una de sus Vidas Paralelas, escrita 125 años después de los hechos y cincuenta años antes de Apiano, añade los datos indispensables para hacernos a una idea más clara de cómo se desenvolvieron los hechos que terminaron con el incendio de la Biblioteca de Alejandría (12). Según Plutarco, al enterarse Cleopatra de la presencia de Julio César en Alejandría, viajó en un pequeño bote, en el que sólo cabían ella y Apolodoro, desde las fronteras de Egipto en donde permanecía hasta cerca del Palacio Real de Alejandría en el que se encontraba Julio César. Una vez allí, consiguió atravesar las puertas del palacio, sin que Ptolomeo XIII o sus espías se enteraran, escondida en una colcha enrollada que cargaba Apolodoro. Cautivado por la inteligencia y arrojo de Cleopatra, a fuer de su belleza, continúa Plutarco, Julio César forzó una reconciliación entre los dos contendores por el trono de Egipto. Durante las celebraciones del acuerdo que regresó a los esposos al Palacio Real y llevó a Cleopatra y a Julio César al concubinato, éste se enteró de un complot en su contra fraguado por Aquilas y Potino y ordenó su muerte. Aquilas consiguió escapar e inició contra Julio César un levantamiento popular que éste (o, muy posiblemente, su amanuense Aulo Hircio) relató en otro de sus Comentarios dándole el nombre de Guerra de Alejandría (13). En el curso de esta "guerra", 20.000 Alejandrinos dirigidos por Aquilas pusieron sitio al Palacio Real de Alejandría y a un sector de la ciudad en los que se había hecho fuerte Julio César junto con 4.000 soldados y mercenarios romanos. En el interior del palacio se encontraban también Cleopatra y Ptolomeo XIII, nominalmente el corregente pero en la práctica rehén de Julio César. Los Alejandrinos, tratando de recuperar a su joven rey, inundaron con agua del mar los canales que proveían de agua fresca al Palacio Real y trataron de apoderarse de las naves de Julio César ancladas en el puerto, pero los romanos, refiere Plutarco, consiguieron agua fresca cavando pozos y Julio César decidió quemar la flota alejandrina y sus propias naves para evitar que cayeran en manos enemigas y cortaran con ellas la posibilidad de recibir refuerzos por el mar. Es entonces cuando, providencialmente para Julio César, el fuego se extendió de las naves a los muelles de madera y de estos a las casas vecinas y a un sector de Alejandría. La conflagración obligó a los alejandrinos a tratar de salvar su ciudad de las llamas y, abandonando el asedio al Palacio Real, dieron tiempo a Julio César para que ocupara la isla de Faro con unas pocas naves que escaparon al incendio. En dicha isla estaba situado el legendario Faro de Alejandría, una de las siete maravillas del mundo antiguo, pero, además, por su ubicación permitía controlar por completo el acceso al puerto y, de sitiado, Julio César se convertía en sitiador. En medio de la confusión reinante las llamas alcanzaron también la Gran Biblioteca que, afirma Plutarco, quedó destruida, pero no hace cálculos sobre las posibles pérdidas.

Pero en Antonio, otra de sus Vidas Paralelas, sí hace cálculos, aunque no con respecto a las pérdidas de libros en la Biblioteca de Alejandría sino con respecto a un extraño método para recuperar el esplendor de la biblioteca destruida y, de paso, ganar el corazón de una dama: robar bibliotecas. Entre seis y siete años después del incendio de la Biblioteca de Alejandría, poco después de la "alianza" entre Marco Antonio y Cleopatra, en una de sus campañas como miembro del segundo triunvirato, Marco Antonio se tomó la ciudad de Pérgamo seguramente con varios propósitos políticos, económicos y personales, pero uno de estos era obsequiarle a Cleopatra como regalo de bodas la Biblioteca de Pérgamo con sus 200.000 volúmenes (14). No queda claro si estos alcanzaron a ser trasladados o no a Alejandría, pero sí hay evidencias históricas y arqueológicas de que por esa época entró en funciones una nueva Biblioteca de Alejandría, llamada por algunos la biblioteca hija, localizada ahora en un anexo del Serapeum, lejos de su antiguo lugar en el interior del Museion vecino al puerto (15).

Suetonio, contemporáneo de Plutarco, consignó información fragmentaria sobre la Guerra de Alejandría en El Divino Julio (16), su biografía de Julio César en Los Doce Césares, pero por ninguna parte aparece en ésta mención alguna al incendio de la biblioteca. Sin embargo, hecho bastante extraño dada la incoherencia que genera, en Domiciano, otro de sus Doce Césares, refiere Suetonio el interés de este emperador por recuperar la biblioteca quemada colectando manuscritos en todas partes y enviando escribas a Alejandría tanto para copiar como para corregir manuscritos (17). Es como si un censor, interesado en borrar la conexión de Julio César con la desaparición de la Biblioteca de Alejandría, hubiese andado metiendo su mano en épocas de escribas o de copistas impidiendo aquí y allá que se reprodujeran ciertos párrafos 
comprometedores para la divinidad del Divino Julio, pero hubiese cumplido su cometido sólo a medias: borró las referencias directas al asunto (por ejemplo en El Divino Julio) pero no pudo borrar toda alusión así fuese indirecta (como en Domiciano) a una pérdida que llamó la atención de tantos.

Dión Casio, doscientos cincuenta años después de los hechos, refiere en su Historia Romana, basándose muy probablemente en fuentes diferentes a las de Plutarco, que después de la huida de Aquilas éste se adueñó de las posiciones más ventajosas en la ciudad de Alejandría y a partir de ese momento hubo de día y de noche numerosos encuentros bélicos entre las fuerzas contendientes que dieron lugar a los incendios que destruyeron los muelles, los depósitos de trigo y, también, la Biblioteca de Alejandría "cuyos volúmenes eran los de mayor número y excelencia" (18).

Aulio Gelio, doscientos años depués de la destrucción de la biblioteca, nos da una idea en sus Noches Áticas de lo que pudo ser la Biblioteca de Alejandría, afirmando que constaba de por lo menos setecientos mil volúmenes que habían sido adquiridos o copiados durante el reinado de los Ptolomeos y afirma que fueron todos quemados "durante el saqueo de la ciudad durante nuestra primera guerra con Alejandría", aunque añade: "no intencionalmente, ni por orden de nadie, sino accidentalmente por los soldados auxiliares" (19). Aunque también excluye a Julio César de toda conexión con el incendio (ni siquiera lo nombra, a no ser que "ni por orden de nadie" signifique "no por orden de Julio César"), por lo menos reconoce que la Biblioteca fue destruida durante la Guerra de Alejandría. Dos párrafos antes menciona al Tirano Pisístrato (siglo VI AEC) como la primera persona en establecer una bibliotecas pública en Atenas, biblioteca a la que luego los atenienses añadieron nuevos volúmenes hasta que Jerjes se tomó Atenas (luego de la batalla de las Termópilas en 480 AEC) y se llevó la biblioteca a Persia como botín de guerra. Años más tarde Seleuco Nicátor, el fundador de la dinastía Seléucida que gobernaría los territorios de las antiguas Mesopotamia y Persia hasta los límites con la India a la muerte de Alejandro Magno, siendo aún oficial de Alejandro, retornó la biblioteca de Pisístrato a Atenas.

Amiano Marcelino (20), cuatrocientos años después de los hechos, informándose quizás de la misma fuente que Aulio Gelio, reafirma la cifra de setecientos mil volúmenes perdidos en el incendio de la biblioteca "causado por Julio César". Como si el temor reverencial a hablar mal de el Divino se estuviese atenuando en la cultura latina. En el siguiente párrafo añade que todavía en el siglo IV Alejandría era un foco de atracción para todos aquellos que querían estudiar en el mejor sitio posible: "también el estudio de la medicina -dice-, cuya ayuda es tan necesaria en una sociedad nada frugal ni sobria, avanza [en Alejandría] cada día; el que un médico pueda afirmar que recibió su entrenamiento en Alejandría es recomendación suficiente de sus capacidades".

En César y Cleopatra (21), otra versión cinematográfica de esta conocida historia aunque no del género de las Historical Epics de Hollywood sino del de las comedias románticas británicas, no es Cleopatra quien informa a César del incendio de la Biblioteca de Alejandría, sino Teódoto. César y Cleopatra se basa fielmente en el drama satírico César y Cleopatra (22) de George Bernard Shaw, escrito y representado más de 60 años antes del guión de Mankiewicz. El drama de Shaw retrata a Julio César como el paradigma del arrivista Romano que con algo de suerte pero, sobre todo, con una total falta de escrúpulos, logrará hacerse Dictador. En el acto II, Teódoto, que aún no ha huido al Asia y permanece como rehén de Julio César junto con Ptolomeo XIII, llega exhausto a contarle a aquel que el fuego de las naves que incendió se ha extendido a los muelles y que ahora "la primera de las siete maravillas del mundo muere, la Biblioteca de Alejandría está en llamas". Julio César, displicente, le responde:"¿eso es todo?", y Teódoto le replica: "César ¿pasarás a la posteridad como un soldado bárbaro demasiado ignorante para conocer el valor de los libros?". Julio César trata de defenderse aduciendo que él mismo es autor de varios libros pero Teódoto insiste :"Lo que se está quemando allí es la memoria de la humanidad", a lo que Julio César responde: "Una memoria vergonzosa: que se queme”. ¿Destruirás el pasado?”, arremete de nuevo Teódoto; “...y construiré el futuro con sus ruinas" le responde Julio César agregando, como a quien se le ha ocurrido una maravillosa idea: "Teódoto, maestro de reyes, tú, a quien le importa menos la cabeza de Pompeyo que a un pastor una cebolla pero te arrodillas ante mi, llorando, para rogar en favor de unos cuantos cueros de oveja garrapateados con errores, no puedo darte ahora ni un hombre, ni un jarro de agua [para extinguir el incendio de la biblioteca], pero puedes salir libremente fuera del palacio: ve con Aquilas y pídele prestadas sus legiones para apagar el fuego". Teódoto sale del Palacio Real al que ya nunca volverá. Al final de la escena, Rufio, lugarteniente de Julio César, se alarma al observar que el ejército egipcio avanza como una plaga de langostas por la orilla occidental del puerto acercándose a ellos, pero Julio César no se arredra, antes bien, se congratula de su propia sagacidad mientras ve arder la biblioteca y le dice: "Yo se los insinué, Rufio, han venido a apagar el fuego, la Biblioteca los mantendrá ocupados mientras nos tomamos el faro". A partir de ese momento Julio César ya no está sitiado.

El paralelismo entre las escenas en las que Julio César recibe la noticia del incendio de la Biblioteca de Alejandría en Cleopatra y en César y Cleopatra es contundente: en ambas películas Julio César sabe que ha provocado el incendio de sus propias naves y de las de la flota egipcia pero no tiene conciencia de que el fuego se ha diseminado a los muelles y mucho menos a la biblioteca, en ambas hay un informante, en ambas Julio César le resta importancia al asunto del incendio, en ambas el informante le reclama a Julio César su insensibilidad con respecto a los libros y con respecto al papel de las bibliotecas en la cultura humana, en ambas Julio César desdeña también la cultura y en ambas los informantes tildan de bárbaro a Julio César por dicha insensibilidad. Sin embargo, finalmente, ambas escenas difieren en lo que difieren Hollywood y el buen cine: en Cleopatra Julio César besa 
a Cleopatra y ya nadie se ocupa de la biblioteca que sigue ardiendo, en César y Cleopatra el incendio de la biblioteca le sirve de estratagema a Julio César para escapar al cerco y tomarse la isla de Faro, como parece que ocurrió en realidad según el relato de Plutarco.

George Bernard Shaw era un socialista fabiano, quizás por ello su poco benévolo retrato de Julio César pueda parecer tendencioso, pero, a decir verdad, es incluso más fiel a los relatos de los historiadores más o menos contemporáneos de los hechos que el guión de Mankiewicz-Durrell. Sin embargo la imagen que propone Shaw no es del todo negativa, todavía hay algo de heroica determinación en la manera en que el Julio César de Shaw está decidido a sortear cualquier contingencia para llegar a donde quiere, es todavía una imagen muy benévola si la comparamos con la que propondrá Bertolt Brecht en 1957 en su novela inconclusa Los Negocios del Señor Julio César, publicada un año después de su muerte. Pero Brecht no es un socialista fabiano como Shaw [ni tampoco un comunista como quería el House Un-American Activities Committee, el comité de actividades antiamericanas de la Cámara de Representantes que lo forzó a salir de Estados Unidos de América en tiempos de la guerra fría y del "temor rojo" azuzado por el macartismo (23)]; Brecht es más bien un humanista con formación en los clásicos y en el marxismo como tantos humanistas del siglo XX. Su retrato de Julio César lo muestra como un delincuente ambicioso centrado sólo en sus fines, un verdadero gánster que utilizaba cuanto encontraba a su paso (personas, pueblos enteros, medios de producción, sistemas legales) como si se tratara de objetos para su usufructo, haciéndolos a un lado o destruyéndolos cuando ya no le eran útiles.

De la misma manera destruyó la Biblioteca de Alejandría. Al comienzo no fue algo premeditado sino que, como lo imagina Shaw, el incendio fue una mera contingencia de la batalla, hasta el momento en que Julio César tomó conciencia de que podía aprovechar en su beneficio el giro que estaban tomando los acontecimientos y el incendio de la Biblioteca de Alejandría o el no apagarlo se volvieron deliberados.

Existen guerras en las que el daño infligido a los libros no es un simple daño imprevisto como consecuencia de la mecánica de destrucción y muerte de todas las guerras (daño colateral dicen de manera eufemística los militares cuando hay más que guerreros entre las víctimas humanas de la contienda), sino que se trata de guerras directas contra los libros, contra sus poseedores, contra sus creadores o contra todos ellos.

La Biblioteca de Alejandría no ardió solo una vez, ardió al menos otras dos veces después del incendio fraguado por Julio César durante la Guerra de Alejandría: el segundo incendio destructor ocurrió en el año 272 EC, con motivo de la guerra de Aureliano contra la Reina Zenobia de Palmira, durante la cual las huestes romanas destruyeron por completo la zona de la ciudad en la que se hallaba el Palacio, incluyendo el Museion y lo que se había podido recuperar en esos tres siglos largos de la biblioteca incendiada por Julio César; el tercer incendio tuvo lugar en el año 391 EC, cuando Teófilo de Antioquía, Patriarca Cristiano de Alejandría, queriendo transformar uno de los templos de la ciudad en templo cristiano, desató una serie de revueltas callejeras paganas que llevaron al emperador Teodosio I a apoyar a Teófilo proscribiendo el paganismo y ordenando la destrucción de todos los templos paganos de Alejandría; tarea de la que se encargó una horda enardecida de cristianos que arrasaron a sangre y fuego toda edificación que trajera algún recuerdo del proscrito paganismo incluyendo el Serapeum, que albergaba la biblioteca hija, y el reconstruido Museion, que guardaba lo que quedaba de la antigua biblioteca (24).

Lucien Polastron ha escrito un minucioso y bello libro sobre la destrucción de bibliotecas a lo largo de la historia (25) y en él, además de las tres destrucciones de la Biblioteca de Alejandría, pasa revista a las innumerables bibliotecas que han sido pasto de las llamas a veces por accidente, casi siempre deliberadamente. De todas ellas, la única biblioteca víctima del fuego que el fuego no solo no pudo destruir sino que ayudó a preservar para nosotros, es la de Asurbanipal: hecha a base de tabletas de barro crudo secado al sol, el incendio con el que las fuerzas de coalición de los Medos y Babilonios destruyeron el Palacio de Asurbanipal durante el saqueo de Nínive en el año 612 AEC, derrumbó en efecto el palacio pero vitrificó el barro crudo trasformándolo en las tabletas de cerámica en las que aun hoy los estudiosos tratan de desentrañar el pasado de la cuna de la civilización en la media luna de las tierras fértiles entre el Tigris y el Éufrates (26).

En tiempos de Julio César, en tiempos de Aureliano y en tiempos de Teodosio I los libros de la Biblioteca de Alejandría no pudieron correr con idéntica suerte que los de la Biblioteca de Asurbanipal: no eran tabletas de arcilla, eran rollos de inflamable papiro.

Los griegos tenían dos términos para designar el papiro:

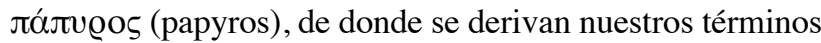
papiro y papel; y $\beta u ́ \beta \lambda$ os (byblos), posiblemente un topónimo derivado de la ciudad fenicia del mismo nombre, de donde se derivan nuestros términos biblioteca, bibliografía y Biblia. Cada rollo de papiro medía hasta 20 metros de longitud y estaba enrollado por uno de sus extremos en un palo (umbilicum). Los autores, escribas y copistas escribían en los rollos en columnas (paginae) transversales a la longitud del rollo y cada columna contaba con 25 a 45 líneas y tenía hasta $21 \mathrm{~cm}$ de ancho (27). Cuenta una leyenda que, en algún momento de la historia, los celos de los Alejandrinos, que querían el monopolio de la producción, copia y venta de libros, impidieron la exportación de papiro tratando de bloquear así a los escribas de la Biblioteca de Pérgamo, pero los pargaminenses se las ingeniaron para escribir en la superficie de rollos de pieles de ternera, de oveja o de cabra adecuadamente preparadas que, desde entonces, denominamos en cada idioma con el equivalente al término latino pergamenum, en honor a la ciudad de origen.

Aunque parezca innecesario, creo que en este punto vale la pena aclarar que cuando me refiero a los libros de la biblioteca 
de Asurbanipal estoy hablando de colecciones de tabletas de arcilla y que cuando menciono los libros de la Biblioteca de Alejandría o los libros de la Biblioteca de Pérgamo, estoy hablando de rollos de papiro (aunque habría que agregar, con respecto a ésta última, de rollos de pergamino). Cuando hablo de libros hablo de un texto escrito por alguien, destinado a ser leído por alguien, susceptible de ser copiado, reproducido y diseminado por diferentes medios, independientemente del soporte físico que sustente dicho texto.

Desde el tercer milenio AEC los asuntos efímeros (datos domésticos o de negocios que no había que rememorar por mucho tiempo o que no había que volver a leer muchas veces o que podrían ser borrados en unos días) se anotaban en tablillas de madera (en latín liber: corteza de árbol, de donde se deriva nuestro término libro) recubiertas con cera, y se escribía sobre la cera con un punzón (en latín stilus, del que deriva nuestro término estilo -literario o de escritura o, incluso, arquitectónico-). Las tablillas de cera eran reciclables, lo escrito se podía borrar calentando un poco la cera y volviéndola a extender sobre la tablilla. Si había muchos asuntos que manejar uno podía tener dos tablillas atadas una a la otra (diptycha) o incluso más, aunque a medida que aumentaba el número de tablillas el volumen de madera se iba haciendo inmanejable. Un número razonable de tablillas enceradas atadas por un costado, cinco o seis, formaba una especie de bloque de madera (de ahí el término latino codex con el que se designó) que se podía abrir tablilla a tablilla.

Uno de los avances más significativos en el desarrollo del soporte físico de los libros tuvo lugar hacia el siglo I EC, cuando a alguien, cuyo nombre quedó perdido en las brumas de la historia, se le ocurrió construir un codex no con liber sino con pergamenum. Allí nació el soporte físico que nosotros llamamos en castellano libro: un paralelepípedo construido mediante la superposición de hojas de pergamino (o de papel o de papiro) cosidas o pegadas una a otra por uno sólo de sus costados y que sirve para consignar en él por escrito un texto (o para leerlo si otro lo ha consignado por escrito previamente). Los latinos que lo inventaron y difundieron mantuvieron el nombre de codex (en castellano códice) para este nuevo soporte de texto basado en pergamino y utilizaron el término membranae para los códices de formato más pequeño y con menos páginas que utilizaron desde entonces como cuadernos de notas (28).

Los códices de pergamino eran más fáciles de transportar que los rollos de papiro y la información anotada en ellos era más fácil de encontrar que en un papiro que había que desenrollar prácticamente por completo para hallar lo que se requería. Hacia el año 85 EC el poeta Marcial, en uno de sus Epigramas, elogia las ventajas de los códices de pergamino: están con el lector en todas partes, sirven como compañeros en los viajes, no necesitan estanterías y caben en una sola mano (además, con socarrona inmodestia, aprovecha el final del poema para informar en dónde venden sus libros) (29). Sin embargo, no fue la publicidad de Marcial la que logró que el códice se impusiera: el auge del cristianismo a partir del siglo III catapultó al códice como formato preferido de escritura y de lectura pues, de alguna manera, era como si los adeptos a la nueva religión quisieran diferenciarse de los paganos guardando por escrito sus creencias y memorias no en rollos de papiro o pergamino sino en códices (30).

Hacia el siglo X los árabes llevaron el papel desde la China a Europa y se comenzaron a producir en el al-Ándalus los primeros códices en papel. Después del siglo XIII, con la aparición en Europa de los primeros molinos de papel [todavía se vacilaba entre si llamarlo "pergamino de trapo" o "pergamino de paper" (31)] el códice se volvió cada vez más barato y accesible y poco a poco llegó a ser el soporte físico estándar de los libros, a tal grado que el término libro terminó siendo utilizado en castellano exclusivamente para designar al códice, y este término cayó en completo desuso. Finalmente el nacimiento de la imprenta terminó por dar ventaja absoluta al papel sobre todos los demás materiales y al códice de papel sobre los demás soportes de escritura y de lectura.

En 1492 un Apocalíptico de la época (la categoría es de Umberto Eco en Apocalípticos e Integrados (32), y fue creada en los años sesenta del siglo XX, pero viene muy bien al caso), el Abad de Sponheim Johannes Trithemius, publicó In Praise of Scribes, un alegato contra los libros de tipo códice impresos en papel (la imprenta apenas tenía 40 años de existencia) augurándole el peor futuro a la cultura si se permitía que desaparecieran los libros tipo códice escritos por escribas sobre pergamino. Su argumento se basaba en parte en que el papel duraría a lo sumo doscientos años mientras que el pergamino podía durar dos mil años (33), y le sobraba razón: muchos de los libros escritos sobre pergamino que leyó Trithemius aún los podemos leer nosotros, mientras que muchos de los libros impresos en papel que él no quiso leer tampoco nosotros podemos leerlos porque esos ejemplares desaparecieron físicamente. Sin embargo, maravillas de la imprenta, esos libros fueron impresos otra vez a partir de las mismas galeradas de los tipógrafos de entonces o de otras nuevas galeradas realizadas a partir de ejemplares de libros a punto de desaparecer y, si bien no podemos leer los "mismos" libros, sí podemos leer esos textos en otros ejemplares de esos libros. El libro de papel y la imprenta, contra lo que temía (o quería) el Abad de Sponheim, no acabaron con la cultura, aunque habría que admitir que cambiaron la cultura y el acceso a la misma gracias a la profusión de libros y a la mayor accesibilidad a los mismos y, bueno, a lo mejor eso haya significado para él el fin de la cultura como la concebía.

Existe al interior del género de la ciencia ficción (o fantaciencia como prefieren llamarla otros), género presente tanto en literatura como en cine, un subgénero que en cinematografía recibe el nombre de Apocalyptic Film cuyas películas, a la manera de Trithemius, se ensañan en describir un periodo post-algo en el que ese algo (epidemias, guerras nucleares, invasiones alienígenas) ha dado lugar a la desaparición de la civilización o de la cultura humanas tal como las conocemos. También existen, obviamente, novelas apocalípticas de cien- 
cia ficción y uno de los temas recurrentes en ellas es el de la desaparición del libro como causa del colapso de la cultura. Dos de los más grandes (y lamentablemente poco difundidos) escritores del siglo XX, Ray Bradbury y Stanislaw Lem, incurrieron, claro está, en el campo de la novela apocalíptica con la desaparición del libro como tema. En Farenheit 451 Bradbury imagina un futuro en el que los libros dan miedo a las autoridades y los bomberos no se dedican a apagar incendios sino a quemar libros mientras algunos memoriosos aprenden libros de memoria para tratar de preservarlos (34); en Memorias Encontradas en una Bañera Lem imagina un futuro en el que una extraña bacteria mutante que crece en y degrada la celulosa destruye todos los libros del mundo, todos los documentos, todos los planos, todo el papel moneda, todo cuanto esté hecho a base de papel: la civilización misma desaparece, como si estuviera también, en esta ácida metáfora de Lem, hecha de papel (35).

Lo cierto es que hasta hace muy poco tiempo la civilización no hubiera podido sobrevivir a ninguno de los dos escenarios planteados en las novelas mencionadas y la predicción de Trithemius se hubiese tornado cierta. En el primer caso, no habría habido tantos memoriosos para guardar en su cabeza todos los libros escritos a lo largo de la historia y, además, ¿cómo consultar, cómo difundir, cómo hacer útiles estos textos cuyo formato de registro y de lectura eran, respectivamente, un cerebro humano y una voz humana?. En el caso de la novela de Lem no habríamos tenido tiempo de copiar de nuevo en piedra, en arcilla, en madera, en metal o en pergamino (el papiro también es celulosa) todos los libros, todos los documentos, todos los planos y todo el papel moneda, antes de que la bacteria diese al traste con todo.

Para fortuna nuestra, los escenarios imaginados por Bradbury y Lem ya no son posibles: cada vez más y más libros y prácticamente todos los nuevos documentos y los planos de nuestros edificios y de nuestras ciudades y de nuestras máquinas y de nuestros medios de producción (y hasta los medios de cambio) están siendo transferidos a soportes físicos de tipo electrónico. Sin embargo, en la actualidad algunos apocalípticos de nuevo corte ven venir, como temían Bradbury y Lem, la muerte de la cultura en la muerte del libro y auguran la desaparición del libro, no como consecuencia de guerras de corte cesariano o por huestes de fanáticos o de nuevos bárbaros iletrados que temen al libro y quieren destruirlo a pólvora y fuego, sino debido al surgimiento del soporte físico electrónico digital del libro. Imaginan que el libro va a desaparecer (y, obvio, "La Cultura", así, con mayúsculas) porque existen las plataformas digitales de lectura de libros en pantallas de computadores y (¡Horror!, ¡Abominación!) porque existen tabletas electrónicas computadorizadas que son tan delgadas como una tablilla encerada y seguramente serán en el futuro tan delgadas como un pergamino y se podrán enrollar como un papiro.

Sin caer en el extremismo de los integrados realmente no hay motivo para dejarnos llevar por estas visiones apocalípticas sobre el futuro de la cultura. La aparición de los soportes digitales significa simplemente que una nueva plataforma física de escritura y lectura acaba de nacer y que estamos asistiendo de manera privilegiada a ese nacimiento. Independientemente de los cambios culturales que este cambio en el soporte físico de libros y revistas traiga consigo, el cambio no tiene por que ser desastroso para la cultura, de hecho el cambio del formato de escritura y lectura en tabletas de arcilla cruda a las tabletas de madera encerada y el cambio de estos elementos al rollo de papiro y el cambio de éste al códice de pergamino y de éste al códice de papel y de éste al libro impreso, no hicieron otra cosa que propiciar el desarrollo de la cultura.

De todas maneras, aunque el nuevo soporte se está desarrollando a pasos agigantados habrá un periodo de transición durante un buen tiempo mientras los escritores, lectores e inventores encuentran el formato para las pantallas electrónicas que sea más amigable, más práctico y más fácil de utilizar y de difundir. Además, todavía falta afinar muchos elementos en cuanto a la producción, edición, distribución, derechos de autor, etc. de los libros y revistas en formato electrónico. De hecho el cambio de los soportes en arcilla a las tablillas enceradas tomó siglos y ambos formatos coexistieron por lo menos durante dos milenios. De igual manera, el cambio de la tableta de arcilla al rollo de papiro también tomó milenios [todavía en el siglo I EC es posible encontrar textos científicos, en este caso un almanaque astronómico, en tabletas de arcilla (36)] y el cambio del rollo de papiro al rollo de pergamino tomó siglos. El cambio de éste último al códice de pergamino tomó también siglos y ambos medios coexistieron durante mucho tiempo. La invención del papel y después el desarrollo de la imprenta lograron un cambio más rápido hacia el formato del libro-códice que conocemos en la actualidad, pero también los libros impresos en papel coexistieron bastante tiempo con los libros manuscritos sobre pergamino. No sabemos cuanto tiempo tomará la transición total de los libros y revistas de papel al soporte electrónico, pero lo cierto es que los libros y revistas en plataforma electrónica nacieron para quedarse. De todas maneras, los libros impresos en papel, tipo códice, seguirán siendo venerados durante un buen tiempo, pero cada vez en usos más restringidos ¿Acaso no regalamos aún pergaminos en ciertas ocasiones solemnes? ¿Acaso no valoramos, y hasta pagamos sumas astronómicas por ellos, los manuscritos originales de determinados autores?

Los libros y revistas cambiarán, pero no desaparecerán, seguirán existiendo en otros soportes físicos. Es necesario perderle el miedo a los adelantos tecnológicos que vienen siempre a mejorar la calidad de la comprensión y la difusión de la producción del conocimiento. Decía Borges que "de los diversos instrumentos del hombre, el más asombroso es, sin duda, el libro", las herramientas son una extensión del brazo mientras los libros son una extensión de la memoria y de la imaginación (37). Habría que corregirlo un poco en el sentido de que no son los libros-códice los que son una extensión de la memoria y la imaginación, también los libros 
de arcilla y de papiro y de pergamino eran una extensión de la memoria. Es la escritura la que es una extensión de la memoria independientemente del soporte físico en que se asiente.

Una de las ventajas de este nuevo formato es la intercomunicabilidad. La capacidad humana de intercambiar conocimiento o de encontrarlo allí donde esté se ve multiplicada cada vez más mediante las nuevas redes electrónicas mundiales en las que, obviamente, estarán interconectados libros, revistas, escritores, investigadores y lectores. Las búsquedas del saber no toman tanto tiempo como en la época de la Biblioteca de Alejandría cuando un erudito debía trasladarse físicamente a Alejandría y vivir allí meses o años hasta encontrar lo que buscaba; una búsqueda tal en la actualidad toma minutos, cuando no segundos. Bueno, queda el problema de quien controlará los medios electrónicos, también es posible "incendiar" libros y revistas en formato electrónico o impedir el acceso a los mismos, nada impide que en el futuro ciertas potencias o corporaciones se hagan con el control total del saber contenido en las redes electrónicas y nada evitaría que un nuevo Julio César tenga la genial idea de "incinerar" esta nueva Biblioteca de Alejandría que es la Internet para obtener quién sabe qué beneficios. Pero este es otro tema y, además, nos adentra de nuevo en el espinoso camino de lo apocalíptico que, aunque también debe ser analizado, será tema de otra ocasión.

Por ahora, la buena nueva: Acta Médica Colombiana arriba a partir de este número de manera plena al soporte electrónico digital. Aunque continuaremos durante un buen tiempo con el soporte físico en papel, desde este momento nuestra revista en la Internet deja de ser simplemente una fotografía o un PDF de la revista en papel colgados en la red para transformarse, con pleno derecho, en una revista electrónica digital con todas las posibilidades de interactividad y de comunicación, de búsqueda y de clasificación que ello conlleva. Por favor ¡disfrútenla!.

\section{Referencias}

1. Whitlock C. Designs on Film: A Century of Hollywood Art Direction. New York: Harper Collins Publishers; 2010: pp 159-161.

2. Malamud M, McGuire DT. Living like Romans in Las Vegas. En Roshel S, Malamud M, McGuire DT (Eds.). Imperial Projections: Ancient Rome in Modern Popular Culture. Baltimore: Johns Hopkins University Press: 2001: pp 249-270.

3. Colleran B, Gielgud J. (Directores). (1964). Richard Burton's Hamlet [Película]. Shakespeare W (Guión). Burton R, Cronyn H, Drake A, Herlie E, Redfield W (Actores). Los Angeles: Image Entertainment. DVD. The National Film and Television Archive at the British Film Institute, 1999.

4. Mankiewicz JL. Cleopatra Shooting Script. Septiembre 18 1961. pp 65-73. Consultado el 18 de mayo de 2011. Disponible en http://www.sendspace.com/file/ xgjchy

5. Adorno T. Teoría Estética. Madrid: Ediciones Akal; 2004: p 316.

6. Mankiewicz JL. (Director). (1963). Cleopatra [Película]. Mankiewicz JL (Guión). Taylor E, Harrison R, Burton R, Cronyn H, Landau M (Actores). Los Angeles: 20th Century Fox. DVD. Award Series, 2006.

7. Pliny. Natural History, Volume V, Books 17-19. Rackham H (Traductor). Cambridge Massachusetts: Loeb Classical Library; 1950: pp. 323-325.

8. Julio César. Guerra Civil, 110, 5-6. Julio Calonge (Traductor). Madrid: Editorial Gredos; 2011: p 265
9. Dueck D. Strabo of Amasia. London: Routledge; 2000: pp. 5-8, 96-106.

10. Lucan. Pharsalia, XX, 486-515. Wilson-Joyce J (Traductor). Ithaca New York: Cornell University Press; 1993: pp 284-285.

11. Apiano. Historia Romana: Guerras Civiles, libros I y II, 78-90. Sancho-Royo A (Traductor). Editorial Gredos; 1985: pp 240-251.

12. Plutarch. Lives, Volume VII, Demosthenes and Cicero, Alexander and Caesar Caesar, 48-49. Perrin B (Traductor). Cambridge Massachusetts: Loeb Classical Library; 1985: pp 555-561.

13. Julio César. Guerra Civil. Julio Calonge (Traductor). Madrid: Editorial Gredos; 2011: pp. 27-36

14. Plutarch. Lives, Volume IX, Demetrius and Antony, Pyrrhus and Gaius Marius. Antony 58, 5. Perrin B (Traductor). Cambridge Massachusetts: Loeb Classical Library; 1920: p 271

15. Barnes R. Cloistered Bookworms in the Chicken-Coop of the Muses: The Ancient Library of Alexandria. In The Library of Alexandria, Centre of Learning in the Ancient World. MacLeod R (Editor), London: I.B.Tauris \& Co Ltd; 2010: pp 61-77.

16. Suetonius. The Twelve Caesars, Divus Julius, 35. Graves R (Traductor). Revised Edition. London: Penguin Classics; 2007: p 17.

17. Suetonius. The Twelve Caesars, Domitian, 20. Graves R (Traductor). Revised Edition. London: Penguin Classics; 2007: p 309.

18. Cassius Dio. Roman History, Volume IV. Book 42, Chapter 38. Cary E (Traductor). Cambridge massachusetts: Loeb Classical Library; 1916: pp 175-176.

19. Aulio Gelio. Noches Áticas. López-Moreda S (Editor). Madrid: Ediciones AKAL; 2009: p 358.

20. Ammianus Marcellinus. The Later Roman Empire: A.D. 354-378. Hamilton W (Traductor). Wallace-Hadrill A (Editor). Penguin Classics; 1986: pp. 252-253.

21. Pascal G. (Director). (1946). César y Cleopatra [Película]. Shaw GB (Guión) Reins C, Leigh V, Granger S (Actores). London: Pascal Film Productions. DVD. Suevia Films, 2010.

22. Shaw GB. Caesar and Cleopatra. En: Three Plays for Puritans. Maryland: Wildside Press; 2003: pp 132-137.

23. Brecht HUAC hearing 1947-10-10. Transcription of some excerpts from an audio recording posted at wikimedia commons. Consultado el 18/06/2011. Disponible en http://en.wikisource.org/wiki/Brecht_HUAC_hearing_(1947-1030)_transcript\#cite_note- 0 .

24. Barnes R. Cloistered Bookworms in the Chicken-Coop of the Muses: The Ancien Library of Alexandria. In The Library of Alexandria, Centre of Learning in the Ancient World. MacLeod R (Editor), London: I.B.Tauris \& Co Ltd; 2010: pp 70-74.

25. Polastron LX. Libros en Llamas: Historia de la Interminable Destrucción de Bibliotecas. México: Fondo de Cultura Económica; 2007: 341 pp.

26. Robson E. The clay tablet book in Sumer, Assyria, and Babylonia. En: ACompanion to the History of the Book. Eliot S, Rose J (Editores). Oxford: Wiley-Blackwell; 2009: pp. 67-83.

27. Roemer C. The papyrus roll in Egypt, Greece, and Rome. En: A Companion to the History of the Book. Eliot S, Rose J (Editores). Oxford: Wiley-Blackwell; 2009: pp. 84-94.

28. Brown MP. The triumph of the codex: the manuscript book before 1100. En: A Companion to the History of the Book. Eliot S, Rose J (Editores). Oxford: WileyBlackwell; 2009: pp.179-193

29. Marco Valerio Marcial. Epigramas. I, 2. Guillen J (traductor). Zaragoza: Institución Fernando el Católico; 2004: p 80.

30. Skeat TC. The origen of the Christian codex. Zeitschrift für Papyrologie und Epigraphik 1994; 102: 263-268. Consultado el 20/06/2011. Disponible en www. uni-koeln.de/phil-fak/ifa/zpe/downloads/1994/102pdf/102263.pdf

31. Dahl S. Historia del Libro. Madrid: Alianza Editorial; 2001: p 50.

32. Eco U. Apocalípticos en Integrados. Barcelona: Tusquets Editores; 1995: 368 pp.

33. Brown MP. The triumph of the codex: the manuscript book before 1100. En: A Companion to the History of the Book. Eliot S, Rose J (Editores). Oxford: WileyBlackwell; 2009: p 191.

34. Bradbury R. Farenheit 451. New York: Ballantine Books; 1987: 208 pp.

35. Lem S. Memorias Encontradas en una Bañera. Madrid: Editorial Bruguera; 1983: $222 \mathrm{pp}$.

36. Robson E. The clay tablet book in Sumer, Assyria, and Babylonia. En: A Companion to the History of the Book. Eliot S, Rose J (Editores). Oxford: Wiley-Blackwell; 2009: p 69.

37. Borges JL. Borges Oral. Madrid: Alianza Editorial; 2006: pp. 9-23. 